\title{
The Allocation of Ambulance to Emergency Centers with the Help of Simulation Techniques Case Study: Birjand City
}

${ }^{1}$ Mohsen Saffarian

2Poriya Rezaei Borji

${ }^{3}$ Seyed Mohammad Purmand

1,2,3 Department of Industrial Engineering, Birjand University of Technology saffarian@birjandut.ac.ir

\section{Doi:10.5901/mjss.2016.v7n4s2p76}

\begin{abstract}
Providing timely and quick medical services to patients and injured people reduces death statistics and increases the satisfaction of the people. This article uses an applied research in which it has been tried to improve the current situation and provide some measures for optimal and appropriate allocation of emergency facilities and number of ambulances available in each base in transportation section of Birjand. In this article Birjand was divided into 15 regions and given the 5 emergency sections available in the city of Birjand and the time interval between regions and centers of the simulation and problem solving was done by the use of MATLAB programming software and finally appropriate allocation was done so that shortest possible time to provide health care services was provided. Information on this study was obtained from the medical emergencies of Birjand.
\end{abstract}

Keywords: Computer Simulation, Optimization Model, Allocation Model, Ambulance, Birjand City.

\section{Introduction}

The emergency section is the first place to provide diagnostic and treatment services in hospitals and treatment sections. Given the importance of speed and accuracy in the delivery of services, appropriate allocation of resources in this sector is of great importance. Primary care to send the patient to the hospital for treatment of critically ill patients is a crucial component. Today, in urban health care systems, generally the survey and initial treatment of critical patients is done by the emergency of hospital and correct, accurate and faster approach in this regard can reduce mortality and disabilities caused by diseases and increase the confidence of people to the system. In this study, in order to achieve the above requirements, allocation pattern of the emergency servicing of Birjand was provided.

\section{Literature Review}

In recent years, some researches have been done on the allocation of ambulances to emergency centers in different cities by the use of various patterns and articles have been provided on the time that it takes for emergency forces to go there and on the assessment of their performance. Khwarizmi et al., in their research studied the status of emergency patients in Shiraz center by the use of the optimal model of transportation. For this study three types of data were studied:

- The number of patients transferred from emergency centers to public hospitals

- The mean distance from the accident site within the various centers to State Hospital

- The number of beds in emergency department

According to the obtained data the transportation model was designed then with the help of lingo software optimal solution was obtained (kharazmi, keshstkaran, parsaii Borazjani, Goudarzi \& Almasian, 2014). Another study in this regard was conducted by Afshar Kazemi et al., with the title of predicating patient model in hospital emergency section using data mining techniques and neural network in which the number of patients was anticipated based on the data of the entrance of patients to emergency room by the use of data mining techniques and Multilayer Perceptron Neural Network (MLP). This study revealed that anticipating the number of emergency patients in estimating the required resources and their proper distribution can improve the quality of services (Afshar Kazemi, Bigdeli, Manouchehri \& Jenab, 2013). Rezai Radmehr et al., on their research evaluated the performance of emergency rooms in Rasoul Akram 
Hospital. (Rezai Radmehr, Mofidi, Saeedi, Farsi, Abbasi, Bidari \& Ashari, 2007). Mehrjardi et al. designed a software model to reduce patient waiting time using arena software (Zare Mehrjardi, Hububati \& Safaii Nick, 2011). Also, kharazmi et al., (2012) in their study located the fire stations in Shiraz city by the use of pairwise comparisons weighting method which is a part of the Analytic Hierarchy Process (AHP). In this study it was revealed that that the number of available stations in the city are not enough to cover the entire city and more than half of the current city limits are needed to locate new stations and also for areas which were out of the radius of existing stations new stations were located (Kharzmi, Emami, Degoshad \& Dehghanian, 2012). Mohammadi in 2013 aimed to provide an appropriate model for location and optimal distribution in Nour's fire stations (Mohammadi \& Pour Ghaiyoomi, 2014). Ahari et al., in a study determined the optimal location for fire stations equipments in which the proposed method was a combination of multi-phase planning and ant colony optimization algorithm (ACO) (Ahari, Ebrahimi, \& Farahman Azar, 2007). In 2014, Rahnama et al. conducted a study on the fire station site location in Urmia city by the use of AHP and GIS (Rahnama, M. R. \& Aftab, 2014). Badri et al., in 1998 presented a paper in which the optimal position for the location of fire station was presented by the use of Multi-criteria planning (Badri, Amr K Mortagy \& Alsayed,1998. Yang et al. in their study aimed to determine the optimal location for fire stations facilities and the proposed method was the combination of a fuzzy multi-objective programming and genetic algorithms (Lili Yang, Bryan \& Shuang, 2007). Alan in a paper examined the strategic planning goals and modeling to support the fire station's position (Alan, 2013).

\section{Problem Statement}

Emergency handles medical emergencies and provide services to injured people and emergency patients that as soon as you receive a call for an ambulance, you should send one as soon as possible. An emergency rescue unit includes the following components:

$\checkmark$ Specialized personnel

$\checkmark$ Emergency specialized equipment, including fixing means and transmission of patient, resuscitation bag with essential medicines

$\checkmark$ Vehicles that vary depending on the place of mission and type of mission (ambulance car, motorbike or rescue helicopter)

In order to provide services there are various types of ambulances:

- Ambulance to transfer the patient type (A): this type has been designed and equipped to transfer the nonemergency patients and has been divided into two categories:

Type $A_{1}=$ suitable for the transfer of one patient

Type $A_{2}=$ suitable for the transfer of one or more patients

- Ambulance to transfer the patient type (B): this type has been designed and equipped to transfer or carry out initial treatment and monitor the emergency patients who do not need special care.

- $\quad$ Ambulance to transfer the patient type (C): this type has been designed and equipped to transfer or carry out special treatment and monitor the emergency patients who need special care.

In this paper, in order to determine the active emergency centers as well as equipment kits in each of the centers of simulation techniques were used to select the appropriate number and type of emergency vehicles. The present study aimed to investigate the emergency system of Birjand and to this end modeling for six months (October, November, December, January, February and March) was done. There are five emergency sections in Birjand, the main care center is in Pasdaran region and other areas are in Masumiyeh, Javadieh, Imam Reza (AS) and Ghafari. The average number of missions per day is 52 and events that often make calls to the Birjand emergency include heart attacks, car accidents, burns, fractures, etc. In this paper, the segmentation was done in a way that the chance of each area to receive call was equal to other areas.

The required information is as follows:

- The number of incoming calls or the interval between the contacts (has an exponential distribution with parameter of 52)

- Time to reach out and provide treatment (duration of reaching out from any care center to any request has an appropriate distribution)

The results and reports include:

- $\quad$ Average waiting time

- The number of times we face a shortage of ambulances

Tables 1 and 2 provide information on existing care centers. 
Table 1. Information of the centers

\begin{tabular}{lc}
\hline Base & Nick name \\
\hline Pasdaran & $\mathrm{P}$ \\
Imam Reza (AS) & $\mathrm{R}$ \\
Ghaffari & $\mathrm{G}$ \\
Javadieh & $\mathrm{J}$ \\
Masumiyeh & $\mathrm{M}$ \\
\hline
\end{tabular}

Table 2. Information of the areas

\begin{tabular}{cl}
\hline 1 & St. Pasdaran- St. Modares \\
\hline 2 & St.Taleghani - St.martyr Montazeri \\
\hline 3 & St. Dolat - St. Shbaniyh - St. Javadieh \\
\hline 4 & St. Martyr Evini - Boulevard Ghaffari \\
\hline 5 & Masumiyeh \\
\hline 6 & Alley Zaferanieh - Narenj - East Gods - Razi \\
\hline 7 & Boulevard Molem - Sarab \\
\hline 8 & Tohid - Imam Musa Sadr \\
\hline 9 & South Emamat - North Emamat \\
10 & St. Engelab - Shohada - Hakim Nazari \\
\hline 11 & St. Martyr Beheshti St. - Mofateh \\
\hline 12 & St. Rajai - St. Musa ibn Ja'far - Dashkry \\
13 & St. Imam Reza - St. Islamic Republic \\
14 & Official Site \\
\hline 15 & Sajjad city - Martyrs Ebadi \\
\hline
\end{tabular}

List of the events of this model are:

TBL [1]: Receiving a phone call

TBL [2]: The end of the Pasdaran ambulance service (per each ambulance service there is an end for the event)

TBL [3]: The end of the Imam Reza ambulance service

TBL [4]: The end of the Ghafari ambulance service

TBL [5]: The end of the Javadieh ambulance service

TBL [6]: The end of the Masumiyeh ambulance service

The variables used in this model are:

Fv (): Interval between calls

FS (): The duration of giving service

$F_{i j}()=$ Travel time from care center $i$ to region $_{j}$

$\mathrm{Si}_{\mathrm{i}}=$ Number of ambulances available in the care center

$\mathrm{Q}=$ Number of customers in queue

$\mathrm{W}$ : depended on the type of patients injury

Table 3 shows the percent of illnesses in which there are phone calls to the emergency center.

Table 3. Information on the type of service

\begin{tabular}{clc}
\hline Row & Illness & Possibility \\
\hline 1 & Respiratory & $\mathbf{0 . 1 5}$ \\
2 & Heart Attack & $\mathbf{0 . 3 5}$ \\
3 & Fractures and Injuries & 0.4 \\
4 & Artery Rupture & 0.1
\end{tabular}

* The array used in this flowchart is list of emergency centers in term of their proximity to the area where the patient has called from.

Zone A: $0<$ RAND <= 1/15, Zone B: $1 / 15<$ RAND <= 2/15, Zone C: $2 / 15<$ RAND <= 3/15 Zone D: $3 / 15<$ RAND <= 4/15 and .... 


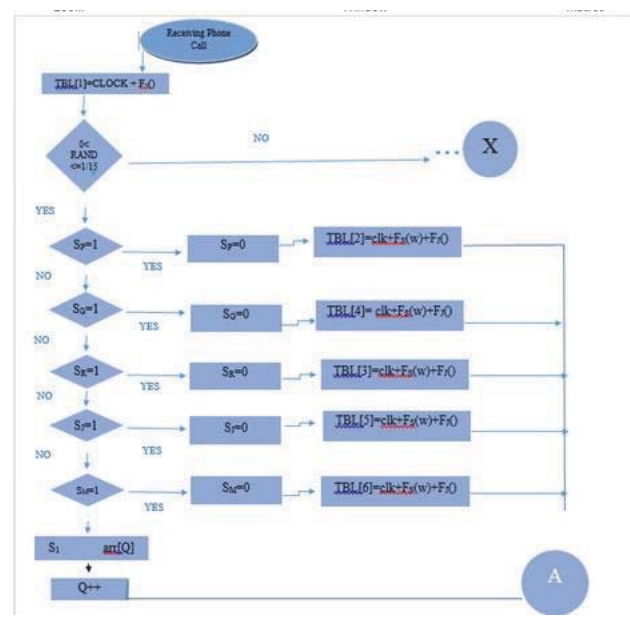

Figure 1.a Flowcharts of various events related to the model

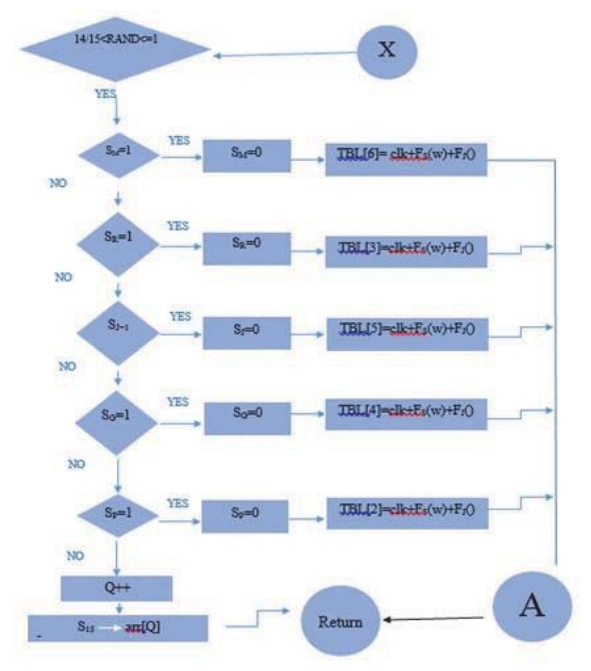

Figure 1.b Flowcharts of various events related to the model

In order to study the event of ambulance return to a care center first of all queue of applicants are checked and in the case of any it must be investigated that whether sending this ambulance will be quicker or based on the faster return, sending other ambulances will be more reasonable so that they can come back sooner and go to other applicants. This action was rewritten for each of the ambulance return events and thus the model was completed.

\section{Analysis of the Results of the Model}

After designing the model, system was simulated for six months the following results were obtained. An increase in the number of available vehicles in the care center is linked to lower the number of deficiencies and latency but the increasing the number of vehicles gas its own cost which must also be considered. In other words, the best scenario is when with the minimum number of ambulances the standard time of providing services is observed. To identify and determine the right combination of vehicles in emergency centers seven different scenarios were considered and models 
based on each of them were solved separately and required results were achieved. In this model the data and input data relating to six months based on the distribution of functions was obtained and then seven different scenarios were considered. Due to the limited number of available ambulances, it is assumed totally seven ambulances are available, and the model must be designed to achieve the best combination of allocation. Therefore, the problem encoded with the help of the programming language MATLAB and the following results were obtained.

Table 4. Number of ambulances in different centers for various scenarios

\begin{tabular}{|c|c|c|c|c|c|c|c|}
\hline Base & Scenario1 & Scenario2 & Scenario3 & Scenario4 & Scenario5 & Scenario6 & Scenario7 \\
\hline P & 1 & 1 & 1 & 1 & 1 & 1 & 1 \\
\hline R & 1 & 1 & 2 & 1 & 2 & 1 & 1 \\
\hline G & 1 & 1 & 1 & 2 & 1 & 1 & 1 \\
\hline J & 1 & 2 & 2 & 1 & 1 & 1 & 2 \\
\hline M & 1 & 1 & 1 & 1 & 1 & 2 & 2 \\
\hline
\end{tabular}

Table 5. Average waiting time and maximum waiting time in different scenarios

\begin{tabular}{|c|c|c|c|c|c|c|c|c|}
\hline & \multicolumn{2}{|c|}{ Scenario1 } & \multicolumn{2}{|l|}{ Scenario2 } & \multicolumn{2}{|l|}{ Scenario3 } & \multicolumn{2}{|c|}{ Scenario4 } \\
\hline Base & Average & maximum & Average & maximum & Average & maximum & Average & maximum \\
\hline $\mathrm{P}$ & $4: 42$ & $6: 13$ & $4: 57$ & $6: 05$ & $4: 42$ & $6: 18$ & $4: 48$ & $6: 48$ \\
\hline $\mathrm{R}$ & $3: 50$ & $7: 30$ & $3: 50$ & $7: 15$ & $3: 01$ & $5: 12$ & $3: 59$ & $7: 17$ \\
\hline G & $5: 05$ & $4: 57$ & $4: 36$ & $4: 21$ & $4: 36$ & $5: 32$ & $3: 25$ & $4: 47$ \\
\hline $\mathrm{J}$ & $4: 42$ & $5: 22$ & $2: 06$ & $5: 38$ & $2: 49$ & $5: 29$ & $4: 54$ & $5: 39$ \\
\hline $\mathrm{M}$ & $4: 16$ & $8: 12$ & $4: 15$ & $5: 39$ & $4: 01$ & $5: 47$ & $4: 47$ & $6: 41$ \\
\hline \multirow[t]{2}{*}{ Total } & $4: 32$ & $8: 12$ & $4: 17$ & $7: 15$ & $3: 25$ & $6: 18$ & $4: 03$ & $7: 17$ \\
\hline & \multicolumn{2}{|c|}{\begin{tabular}{l|l} 
Scenario5 & \\
\end{tabular}} & \multicolumn{2}{|l|}{ Scenario6 } & \multicolumn{2}{|l|}{ Scenario7 } & \multicolumn{2}{|c|}{ Scenario8 } \\
\hline Base & Average & maximum & Average & maximum & Average & maximum & Average & maximum \\
\hline$P$ & $4: 56$ & $6: 56$ & $4: 29$ & $6: 18$ & $4: 42$ & $5: 21$ & & \\
\hline $\mathrm{R}$ & $3: 24$ & $4: 47$ & $3: 59$ & $5: 41$ & $3: 42$ & $5: 20$ & & \\
\hline G & $5: 41$ & $7: 12$ & $5: 30$ & $7: 28$ & $3: 58$ & $5: 49$ & & \\
\hline $\mathrm{J}$ & $4: 29$ & $5: 19$ & $4: 51$ & $5: 51$ & $2: 49$ & $3: 49$ & & \\
\hline $\mathrm{M}$ & $4: 17$ & $5: 38$ & $3: 07$ & 4:04 & $3: 02$ & $4: 58$ & & \\
\hline Total & $4: 71$ & $7: 12$ & 4.21 & $7: 28$ & $3: 35$ & $5: 49$ & & \\
\hline
\end{tabular}

According to international standards, ambulance allocation conditions must be in such a way that patients' waiting time becomes maximum 6 minutes. For this reason seven different scenarios were considered that their details are shown in Table (4). Then, for each scenario the problem was solved and the average waiting time the maximum waiting time for patients were achieved for each mode and a summary was provided in Table (5). As it can be seen in Table (5), the average waiting time in third scenario is better however, the maximum waiting time for the seventh scenario is more appropriate. Therefore, considering the importance of the maximum waiting time the most appropriate allocation was $7^{\text {th }}$ scenario in which both criteria of average waiting time as well as maximum waiting time had better conditions.

\section{Conclusion}

Since the provision of health services to patients and casualties is very important in any society and increasing the speed and quality of service can increase the satisfaction of citizens and consequently the status of a society therefore, allocating appropriate number of ambulance and finding appropriate location for emergency centers can increase the efficiency of health care services. In this study, a question regarding the allocation of ambulances to emergency centers in Birjand as a case study was surveyed. Accordingly, seven different scenarios were considered, and with the help of computer simulation techniques best scenario for ambulance allocation was obtained. Two criteria which should be minimized were the average waiting time as well as the maximum waiting time for ambulance allocation. Regarding the above mentioned cases the answer to the study question is to have an ambulance in Pasdaran, Imam Reza and Gafari centers as well as two ambulances in Javadieh and Masumiyeh that with this allocation an average waiting time of 3:35 and maximum 5:49 minutes were obtained respectively. Further researches can be done seamlessly for locating, routing and allocating and appropriate solutions will be achieved. 


\section{References}

Afshar Kazemi, M.A., Bigdeli, N., Manouchehri, J., \& Jenab, I. (2013). Predicting A Pattern of Patient Arrival at Emergency Department by Using Data Mining Technique and Neural Network Model, Journal of Hospital, No. 4, 47, 73-80.

Ahari, T., Ebrahimi, S., \& Farahmand Azar, B. (2007). Optimize the number and location of fire stations in an area using a combination of fuzzy and ant colony optimization algorithm, 1st Joint Congress on Fuzzy and Intelligent Systems.

Alan, T. M. (2013). Optimizing the spatial location of urban fire station, Fire Safety Journal, 62, pp 64-71.

Badri, M. A., Amr, K., Mortagy, A. K. \& Alsayed, C. A. (1998). A multi-objective model for locating fire stations. European Journal of Operational Research, 110(2), pp 243-260.

Kharzmi, M. R., Emami, F., Degoshad, M. H. \& Dehghanian, M.M., (2012). Evaluation and Optimization of fire station locations using GIS (Case Study of Shiraz), Second Conference on Disaster Management.

Kharazmi, A., keshtkaran, A., parsaii Borazjani, P., Goudarzi, S., \& Almasian Kia, A. (2014). Allocation of Cardiovascular and Internal Emergency Patients in Shiraz Emergency Stations: presenting the optimal pattern using transportation model. Journal of Health \& Development, Volume: 3, Issue: 4, 313-322.

Lili Yang, L., Bryan, F. J., \& Shuang, H. Y.,(2007). A fuzzy multi-objective programming for optimization of for fire station locations through genetic algorithms, European Journal of Operational Research,181(2), pp 903-915.

Mohammadi, J., \& Pour Ghaiyoomi, H. (2014). Spatial Analysis and Location of Firehouse of Noorabad City Using GIS'. Journal of Geography and Planning, Volume 18, Issue 48, 279-298.

Rahnama, M. R. \& Aftab, A. (2014). Locate fire stations Orumiyeh using GIS and AHP, Geography and Development Iranian Journal, 35, 153-166.

Rezai Radmehr, M., Mofidi, M., Saeedi, H., Farsi, D., Abbasi, S., Bidari, A., \& Ashari, N. (2007). Quality assessment of prehospital care service in patients transported to hazrat-e- rasoul akram hospital. Medical journal of tabriz university of medical sciences, Vol 29, No 3, 43-46.

Zare Mehrjardi, I., Hububati, M., \& Safaii Nick, F. (2011). Improvement of Waiting Time for Patients Referring to Emergency Room Using Discrete Event Simulation.. The Journal of Shahid Sadoughi University of Medical Sciences, Vol. 19, No. 3, 302-312. 